\title{
DISPONIBILIDADES HÍDRICAS Y MODERNAS TÉCNICAS DE EMBALSE EN EL CAMPO DE ALICANTE
}

\author{
Alfredo Morales Gil \\ Concepción Bru Ronda.
}

\begin{abstract}
*Este trabajo ha sido realizado dentro de los planes de investigación de la Comisión Asesora de Investigación Científica y Técnica. En él se incluye en la Comarca del Campo de Alicante al municipio de Monforte del Cid, ya que algunos de los embalses analizados y su zona de influencia se sitúan entre este municipio y el colindante de Agost.
\end{abstract}

\section{INTRODUCCIÓN}

La tradicional búsqueda del agua constituye una constante en sectores como el que nos ocupa, donde la escasez de precipitaciones junto a las altas temperaturas y la litología deparan una intensa aridez, confiriendo al agua la condición de recurso escaso y por ello más preciado. En el Campo de Alicante la secular tarea de incrementar los caudales exiguos ofrecidos por las fuentes naturales, así como su almacenamiento para su posterior utilización, ha constituido una pauta a lo largo de la historia, mereciendo la admiración de los observadores ${ }^{1}$. Este bien social, no obstante, alcanza su máximo interés desde antaño en el sector agrícola, debido a que parte de las condiciones físicas son inmejorables para la agricultura de no faltar el agua ${ }^{2}$. En base a esto, las más diversas técnicas fueron utilizadas en estas tierras desde época romana. La primera obra de gran magnitud, el Pantano de Tibi, data del siglo XVI. Ya con posterioridad y ante la continua deficiencia de caudales se intentaron soluciones quiméricas, como el de trasvasar agua desde el Júcar, el Ebro, o desde las Lagunas de Ruidera, proyectos que más recientemente se plasmaron en el Trasvase del Tajo al Segura. Pero este último plan no beneficia aún a los agricultores del Campo de Alicante, y la escasez de las arterias fluviales locales sigue patente. Debido a ello y con bastante anterioridad (desde la mitad del siglo) los propietarios agrícolas se plantearon la necesidad [20] de conseguir el agua de procedencia hipogea o epigea y, una vez obtenida, en mayor o en menor cantidad, almacenarla para regular su distribución, e incluso más recientemente, debido a procesos de salinización, realizar la mezcla de líquidos de distintas procedencias y con diferentes contenidos salínicos a fin de hacerlos utilizables en la agricultura.

Con estas pretensiones, en un primer momento, se construyeron estanques y balsas de mampostería alimentadas por fuentes locales e incluso nutridas por los caudales de las ramblas y ríos de la comarca. Pero ya en la década de los 60 estas construcciones de técnica sencilla adquirieron formas más sofisticadas capaces de albergar mayores cantidades de agua procedente de otros sectores ajenos a los contornos. Con ello, las huertas y el regadío dejaron de ocupar un sector limitado a los fondos de valles cuaternarios, vinculados a fuentes y mantos freáticos exiguos que se agotaban con facilidad, trasladándose a sectores de piedemontes igualmente aptos para la agricultura de regadío. En este proceso de mutación paisajística hay que resaltar la

${ }^{1}$ CAVANILleS, A. J. (1795-97): Observaciones sobre la Historia Natural, Geografia, Agricultura, Población y Frutos del Reyno de Valencia. Madrid. Imprenta Real, 2 vol., pág. 249, tomo II.

${ }^{2}$ LÓPEZ GÓMEZ, A. (1951): «Riegos y cultivos en la Huerta de Alicante, evolución y estado actual». Estudios Geográficos, N. ${ }^{\circ} 45$, pág. 705. 
importancia de los cultivos de exportación ${ }^{3}$ instalados desde los 60 en el sector surestino peninsular, donde el agua constituye la clave de su sustento, pese a su rareza y carestía, siendo sólo estos productos valiosos para la exportación los que pueden rentabilizar su usufructo y con mayor razón su prospección, captación y traslado a los campos.

De los estanques de mampostería se pasó a las balsas impermeabilizadas con fibras de plástico de entre 5.000 y $10.000 \mathrm{~m}^{3}$, que, posteriormente, en manos de Sociedades Agrarias de Transformación y empresas privadas evolucionaron hasta verdaderas obras de ingeniería hidráulica, que se pueden contemplar en sectores del Campo de Alicante, como Busot, Monforte o Agost, con capacidades de hasta $1,5 \mathrm{hm}^{3}$. La proliferación de este tipo de embalses ha sido vertiginosa desde los años 70, contabilizándose la cifra aproximada de sesenta de ellos, de los cuales una tercera parte son superiores a 100.000 metros cúbicos. La existencia de estos embalses tiene diversos matices, entre los que destacan su ayuda a las transformaciones del paisaje del agro alicantino y la mejora de las condiciones socioeconómicas de estas áreas. Son esos impactos, así como el fenómeno embalse, lo que se va a analizar en las páginas que siguen.

\section{EL APROVECHAMIENTO TRADICIONAL DE LOS ESCASOS RECURSOS HÍDRICOS EN EL CAMPO DE ALICANTE}

\section{La utilización del agua hasta el siglo XIII}

Las primeras noticias que se tienen sobre los aprovechamientos de aguas, así como de los sistemas de riegos en el Campo de Alicante, se remontan a la [21] época romana, aunque son sólo informaciones parciales que llegan a través de cronistas como el Dean V. Bendicho ${ }^{4}$, el cual al hablar sobre la población de Alona y siguiendo a Pomponio Mela, dice: «la ciudad de Alicante es otra cuyas ruinas se ven hoy en nuestro término en el paraje de la Isleta, casi a la orilla del mar... en este sitio se ven hoy muchas ruinas... Anorias y albercas con las que se regaban las tierras que servían de jardines». En este paraje de Campello donde se situó Alona cita Bendicho «y desde las fuentes del río y Castillo de Aguas hasta esta población de Alona se descubre en partes un acueducto bien hecho y costoso y en algunas partes la peña cortada. Por el cual venía a sus fuentes o huertas de Alona el agua». Luego haciendo referencia a las palabras de Viciana, continúa: «alude a la acequia de los enamorados. Esta antiquísima fábrica, obra de romanos y no de moros, era una acequia que pretendieron sacar desde lo más alto de la sierra en que hoy está construido el Pantano quizás para traer agua de la Alcornia, fuente que debió ser entonces abundantísima... véense estos vestigios desde la misma pared del Pantano, y de la sierra en quien estriba su fábrica, ya por Montnegre hacia el Moralet y Raspeig, términos que si tuvieran agua fueran de indudable provecho, hasta llegar a la Cañada que decimos del Gobernador y allí podía venir hasta esta ciudad muy cavallera y anivelada ${ }^{5}$. Otro indicio es la parte del acueducto romano que todavía en el siglo XVII conoció y anotó el benedictino Bernard de Montfauconm que desde la Alcoraya traía el agua a Els Antigons hoy Benalúa ${ }^{6}$. Si bien es verdad, estas

\footnotetext{
${ }^{3}$ COSTA MAS, J. (1983): «La agricultura de los cosecheros-exportadores de tomate en Alicante». VIII Coloquio de Geógrafos Españoles, septiembre de 1983. Páginas mecanografiadas.

${ }^{4}$ BENDICHO, Doctor D. V. (1640), Crónica sobre la muy Ilustre, Noble y Leal ciudad de Alicante. IDEA. Excma. Diputación Provincial de Alicante. Edición resumida y anotada por don Francisco Figueras Pacheco, pág. 13.

${ }^{5}$ BENDICHO, Doctor D. V. (1640). Opus cit. pág. 17.

${ }^{6}$ RAMOS HIDALGO, A. (1983). Evolución urbana de Alicante. Tesis Doctoral. Departamento de Geografía. Universidad de Alicante, pág. 97.
} 
informaciones no detallan el sistema de riego y su uso concreto, ni en quién recaía la propiedad del agua, pero nos hablan de esa preocupación constante por explotar los escasos recursos y utilizarlos.

Excepto estas noticias y hasta la reconquista, no se conocen datos sobre aprovechamiento de aguas y sistemas de riego, aunque éstos fueron utilizados con toda seguridad por los musulmanes, como demuestra la toponimia y diversas denominaciones, y especialmente la pronta organización efectuada por los cristianos merced a la existencia de las acequias y a la tradición del regadío ${ }^{7}$. Es decir, los musulmanes intensificaron notablemente el regadío, quizás lo renovaron en parte y extendieron en las zonas bajas, pero no debieron ser creaciones absolutamente nuevas y los canales antiguos, romanos, se siguieron utilizando, por lo menos parcialmente.

Entregadas las tierras conquistadas a sus pobladores, por el rey Alfonso X y su esposa, Dña. Violante, dio este monarca en Murcia en 28 de agosto de 1254 un privilegio concediendo a Alicante y su término todas las tierras y [22] aguas hasta Novelda, Aspe el Viejo y el Nuevo, Monforte, Agost, Busot y Aguas. El Concejo de Alicante repartió las aguas entre los huertanos en proporción a las tierras. Estas aguas eran tanto las pluviales como las aluviales que discurrieran por el río Montnegre y que procedían de los términos de Castalla, Onil y Tibi ${ }^{8}$. El Concejo de la ciudad distribuyó el fluir del río Montnegre en unidades de hora y media o hilos, repartiéndose 336 de éstos, que formaban un turno de veintiún días, llamado mártaba. Aparte se hicieron otros 336 hilos de agua de avenida o pluviales de distribución eventual.

Cuando Alicante pasó a formar parte del Reino de Valencia, en 1304, se mantuvo este régimen de propiedad. Para evitar que el agua pasara a otras personas distintas de los labradores, el rey Juan I dio un privilegio en Monzón a 1 de marzo de 1389 prohibiendo legar o vender aguas a Iglesias o personas que no tuviesen tierras, y en todo caso no podían adquirir más que la necesaria para el riego. Esto no se cumplió, por lo menos en lo referente a las Iglesias, pues a finales del siglo XVI todavía se hicieron donaciones. Ya desde entonces la separación del agua y la tierra marca una diferencia esencial con los regadíos del Turia, Júcar y Segura, donde siempre estuvieron unidos ${ }^{9}$.

\section{Los regadios de la Edad Moderna}

Como el caudal del río era tan escaso e irregular, se planteó la necesidad de construir un embalse en el término de Tibi, cuya obra fue pagada por el Común y administrada por el Concejo de Alicante. Concluidas las obras a fines de 1594 se procedió a una nueva ordenación dividiendo el agua en dos partes llamadas hilas o dulas. Se reconocieron a los antiguos poseedores sus 336 hilos de hora y media de aguas fluyentes separadas de la tierra (dula de agua vieja) y se distribuyeron las obtenidas del embalse (dula de agua nueva) en otros 336 hilos, correspondiendo a cada uno de ellos 83 tahúllas, a razón de minuto por tahúlla adscrito inseparablemente a la tierra.

Tras diversos reglamentos y vicisitudes, entre los que cabe destacar la creación de la «Dula del Rey» para vender agua con destino a pagar las deudas de construcción, la realización del azud de San Juan, que recogía las aguas sobrantes de avenida provenientes del pantano de Muchamiel o viejo, propiedad de los que intervinieron en la obra, así como las reparaciones que

${ }^{7}$ LÓPEZ GÓMEZ, A. (1974), «El origen de los riegos valencianos. Los canales romanos». Cuadernos de Geografia, número 15, págs. 4 y siguientes.

\footnotetext{
${ }^{8}$ MARTÍNEZ MORELLA, V. (1951), Privilegios de Alfonso X a Alicante, pág. 9.

${ }^{9}$ LÓPEZ GÓMEZ, A. (1951), Opus cit. pág. 711.
} 
sufrió el pantano en el año 1601 y 1697 y que interrumpieron los riegos, no reanudados con normalidad hasta $1738^{10}$ se llega a los Estatutos, vigentes hasta la actualidad, que datan de las Ordenanzas otorgadas por la reina Isabel II en 24 de enero del año 1865. El Reglamento estipula que la Huerta de Alicante se compone de 30.660 tahúllas de tierra, que en los términos de Alicante, Muchamiel, San Juan y Villafranqueza tienen derecho adquirido por [23] antiguos repartimientos a ser regados con las aguas que se reúnen en el llamado Pantano de Alicante, situado en el término de Tibi, y de las demás que de la parte de abajo de dicho edificio van a la huerta, o que se adquieran por consecuencia de trabajos y obras que se hagan por otros medios, regándose también las tahúllas cuyos dueños tengan derecho, del distrito rural de Montnegre, en los términos de Alicante y Jijona. Según estos reglamentos ${ }^{11}$ no se puede legar, donar, vender, permutar, empeñar, arrendar, ni de ningún modo, cantidad de agua vieja a persona que no tenga nueva, ni cantidad alguna de ésta separadamente de las tierras que la tienen anexa.

La escasez de agua, así como la coexistencia de estas diversas clases de agua, plantea un gran número de problemas jurídicos, ya que la distinción entre los poseedores de agua vieja (aguas pluviales y naturales), los cuales podían disponer plenamente del agua y arrendarla y venderla independientemente de la propiedad, y los nuevos beneficiarios del agua embalsada en el pantano, agua nueva, a los cuales el agua les estaba adscrita a la tierra, dejaba a estos últimos en interioridad respecto a los primeros, hecho que suscitó disputas. El conflicto no llegó nunca a solucionarse y mientras los poseedores de agua vieja podían comerciar con ella al disponer de más en relación a sus tierras, el propietario de agua nueva sólo podía utilizar aquella que le correspondía o arrendar o comprar agua vieja, vendida por sus dueños en época de escasez a precios altos. Varias veces elevaron sus quejas los poseedores del agua nueva, pero se siguió manteniendo el sistema tradicional de riego. Así, en la práctica y pese a la reglamentación, el labrador que no quisiera consumir su agua, su turno, lo vendía a otro que lo necesitaba, creándose un mercado que, no estando reglamentado sobre el papel, se basaba en lo consuetudinario ${ }^{12}$.

El régimen y administración de las aguas de riego de la huerta de Alicante está a cargo de un Sindicato de riegos que consta de trece Síndicos. Y en lo que se refiere a su distribución, tras llegar al azud de Muchamiel, que tiene la misión de recoger las aguas de avenida (así como las de San Juan y Campello aguas abajo), pasan a la red de acequias, si bien estos azudes de fábrica hoy sólo sirven para dirigir el agua y no para embalsarla. Por ello y para regular el riego normal se construyó en el año 1842, al comienzo de la acequia mayor, un gran estanque llamado «el Pantanet», que fue agrandado en 1874.

Para el sistema de riegos se utiliza una acequia Mayor o eje que corre desde el azud de Muchamiel por toda la huerta, pasando cubierta por aquel pueblo y por San Juan, acabando en el mar. De ella arrancan las acequias de primer orden, llamadas brazales, de distinta longitud, en número de 22, que a su vez [24] se subdividen en hijuelas, y éstas en subramales. Esta red de acequias pertenece al sindicato, y a él corresponde su conservación.

En relación al reparto de agua y debido a la escasez de caudales, la distribución antes citada no se produce, lo que obliga hoy en día a suspender el riego hasta que se acumula el agua necesaria, con lo que las tandas se ven alargadas en varios meses. En la actualidad se han unido las dos dulas (agua nueva y agua vieja) en una llamada «doble», con un caudal de unos 150

${ }^{10}$ LÓPEZ GÓMEZ, A. (1951), Opus cit. pág. 714.

11 SINDICATO DE RIEGOS (1887), Reglamentos para el aprovechamiento de las aguas de riego de la Huerta de Alicante.

12 GIMÉNEZ LÓPEZ, E. (1981), Alicante en el siglo XVIII. Institución «Alfons el Magnanim». Excma. Diputación Provincial de Valencia, pág. 449. 
1/seg., significando 9.000 litros por minuto y tahúlla o 72 litros por ha, siendo necesarios de 500 a $1.000 \mathrm{~m}^{3}$ por ha y riego; el agricultor necesita reunir los derechos de otros regantes que no la utilizan para en esa tanda poder regar. En el año 1979, por ejemplo, sólo se dispuso de 2 tandas ${ }^{13}$. En el siglo pasado las condiciones eran mejores. Siguiendo a López Gómez, en el sexenio 1860-65 se lograron una media de 14 martabas, con lo que se consigue casi igualar la cifra teórica de tandas, existiendo un año máximo de 17 y uno mínimo de 10. En nuestro siglo ha empeorado mucho la situación, dándose para el decenio 1970-79 un promedio de 9,4 tandas, existiendo un máximo de 16 (1974) y un año mínimo de 2 (1979).

No han visto la luz las posibles soluciones pensadas para compensar este problema de escasez, ni los planes de recrecer la presa del embalse en ocho metros de altura, lo que aumentaría la capacidad del mismo en 2,7 millones de metros cúbicos de agua (hoy puede embalsar 3,7 millones de metros cúbicos).

Por su buena calidad el agua alcanza alto precio, siendo alrededor de 500 ptas. la hora, a 150 1/seg. cuando hay abundancia, pero en años de sequía puede llegar a 2.000 y 3.000 ptas., e incluso superar esa cantidad. Por la mayor necesidad de riego los precios más altos se estiman en verano, siendo los meses de julio y agosto los que ostentan las cotas más elevadas.

Sobre las aguas de avenida que discurrían por el término y que tenían una distribución eventual como se dijo, se hicieron en principio otros 336 hilos. Este agua era llamada también pluvial o de ventura, por su característica aleatoria, y de partidor pues el beneficiario colocaba una especie de compuerta (partidor) para dirigirla a sus tierras; sus unidades se denominaban ya venturas o partidores en vez de hilos, siendo de análoga duración. Como el reparto era eventual, estaban adscritos a un determinado día del mes (el segundo lunes, el tercer jueves, etc.). Este agua adquirió también personalidad propia y podía enajenarse la propiedad, como la normal de río, ya que parece que en un principio era de propiedad particular, perteneciente a los primitivos dueños del agua vieja, pero que tras las Ordenanzas de 20 de noviembre de 1740 pasaron al Común. Este agua de carácter eventual no se embalsa en el pantano, sino que se recoge por los azudes de Muchamiel, San Juan y Campello. Se utiliza para aumentar el caudal de riego ordinario y de estas sobrantes de avenida percibía el sindicato una cierta cantidad por tahúlla [25] regada (5 ptas. en 1951), comprobación que realizaba el acequiero recorriendo las tierras, repartiendo dichas aguas de avenida dos martaveros eventuales ${ }^{14}$.

\section{La búsqueda de caudales desde el siglo XVIII hasta fines del XIX}

Este complejo sistema de riegos que se ha esbozado cubría únicamente la denominada Huerta de Alicante ${ }^{15}$, dejando fuera de su alcance un gran porcentaje de la comarca del Campo de Alicante, que debía de beneficiarse de otro tipo de riegos si es que se daban, o quedar relegados a los inmensos secanos o a cerros y lomas estériles y yermas. Excluidos los sectores de la Huerta, la generalidad para el resto de la comarca eran tierras de secano y baldíos y los cultivos dominantes eran los cereales, barrilla, y arbolado, con predominio de almendros, algarrobos, olivos e higueras. No obstante cabe señalar algunos sectores en los que la existencia de pozos de los que se extraía el agua mediante zúas, permitía un cultivo hortícola de relativa extensión. Otros manantiales, ubicados en lugares de contacto entre materiales secundarios y

\footnotetext{
${ }^{13}$ GINER GONZÁLEZ, M. (1980), Mutxamel: Estudio demográfico y económico de un municipio del Camp d'Alacant. Dpto. de Geografía. Universidad de Alicante, pág. 165.

${ }^{14}$ LÓPEZ GÓMEZ, A. (1951), Opus cit. págs. 714-726.

${ }^{15}$ Comprende la Huerta el término de San Juan y parte de los de Muchamiel y Campello (con dichas localidades) y de Alicante (Tángel, Villafranqueza, Santa Faz, etc.).
} 
terciarios, facilitaban a su vez el riego. Para el siglo XVIII tenemos noticias de algunos de ellos, como el existente en la finca propiedad de los dominicos en la Saborida, el manantial termal de Font-Calent, la denominada Font del Carranxalet entre la Cañada y el Raspeig, los pozos existentes en el Garbinet y la denominada Fuente de la Casa Blanca o Fuensanta en San Blas, cuya importancia no debió ser desdeñable, pues contaba con una tabla de regantes por la que se regulaban los turnos de riego, siendo utilizada, a su vez, para el abastecimiento de la ciudad junto con la Font del Batle. En ocasiones se aprovechaban, igualmente, el agua de lluvia recogida en balsas, como las dos de la partida de El Toll. La existencia de estos riegos con aguas vivas o procedentes de norias eran, en la mayoría de los casos, poco relevantes y las parcelas cultivadas con ellas sólo cubrían el consumo de sus propietarios ${ }^{16}$.

También en el término de Agost las aguas eran escasísimas, como cita Cavanilles ${ }^{17}$ a fines del XVIII, quien únicamente señala las obras que se realizan para acopiar las aguas de varios manantiales que se perderían sin utilidad alguna, llevadas a cabo por D. Pedro Andrés Visedo, el cual las recogía mediante un estanque. Las tierras de secano sólo «reciben algún riego en tiempos de lluvias, a cuyo fin se han abierto canales que se comunican, y tomada el agua en los sitios altos de las arroyadas y barrancos se conduce largo trecho a las heredades. Alguna vez en julio rebosan de agua los canales [26] sin descubrirse nubes, por haber llovido en los montes, cuyas vertientes caen a la espaciosa hoya donde está Agost y demás pueblos occidentales «...» Quisieran los habitantes hallar aguas a todo precio, y conducirlas de cualquier distancia...» ${ }^{18}$.

En lo referente a Monforte, Cavanilles ${ }^{19}$ elogia ya en su época la huerta, que junto a las de Aspe y Novelda conforman un auténtico vergel. «En Monforte hay agua para pocas más de 500 tahúllas. Riéganse éstas con el agua de dos fuentes que brotan junto a la misma villa; y es lástima no sean más copiosas por hallarse ya dispuestas para el riego, multitud de campos, que sólo lo consiguen cuando llueve, lo cual se verifica pocas veces». Señala a la vez que se beneficia de las aguas de avenida que sean canalizadas a través (del Vinalopó) «rambla o río» que pasa por la parte oriental de las huertas de Novelda y que antes de llegar a este municipio se sumen en el cascajo de arena corriendo largo trecho ocultas, y vuelven a salir caminando hacia Monforte. Recogía también las aguas que desde los montes bajan ocultas hasta muy cerca de la villa.

Como se aprecia de lo expuesto, la existencia de otros recursos en el Campo de Alicante, como los procedentes de norias o de zúas y pozos artesianos eran poco relevantes y no cubrían las necesidades para el regadío, que se ubicaba en rodales de huerta marginales y periféricos a los municipios, prodigándose con mayor extensión los secanos que se nutrían de riegos eventuales y esporádicos dominando cerros, lomas y glacis totalmente abancalados de los sectores adyacentes a los poblados que encontraremos a principios del siglo XX parcialmente abandonados, contribuyendo con ello a fomentar los procesos de erosión ${ }^{20}$.

La mayoría de los caudales procedentes de norias y fuentes únicamente abastecían el consumo de la ciudad de Alicante, que presentaba una notable carestía. Según Silvio Viñes

${ }^{16}$ GIMÉNEZ LÓPEZ, E. (1981), Opus cit. pág. 88.

${ }^{17}$ CAVANILLES, A. J. (1795-97), Opus cit. pág. 254.

${ }^{18}$ CAVANILLES, A. J. (1795-97), Opus cit. pág. 255.

${ }^{19}$ CAVANILLES, A. J. (1795-97), Opus cit. pág. 266.

${ }^{20}$ MORALES GIL, A. y otros (1982), «Condiciones morfológicas y chubascos de fuerte intensidad horaria en la cuenca vertiente del Barranco de las Ovejas (Alicante). En Lluvias torrenciales e inundaciones en Alicante. Instituto Universitario de Geografía. Univ. Alicante, págs. 25-98. 
Martínez $^{21}$, a fines del XIX la ciudad se nutría con 129.600 litros al día, que aforaban unas fuentes situadas en la Alcoraya, propiedad del Marqués de Benalúa desde 1881, y que eran transportadas a la ciudad y puestas a la venta pública en tres fuentes (a 5 céntimos de peseta por cántaro, equivalente a 10 litros). A éstos se añadían otros 100 litros al día procedentes de las norias de pago de Torregrosa en San Vicente del Raspeig, que se distribuían por la cañería municipal, y además se sumaban las aguas que de distinta procedencia a las marcadas, en su mayoría de anorias, daban un caudal de 50.000 litros. [27]

Estas aguas, similares en nacimiento a las anteriores, no se utilizaban para el regadío, ya que la ciudad con estos caudales poseía insignificante dotación de aguas potables, hecho este que llevó al ingeniero Silvio Viñes Martínez a proyectar el Canal del Cid, alimentado por los volúmenes de los pozos artesianos de Sax, en número de cuatro, de los cuales se extraerían en un primer momento 110 1/seg., de los que 100 se invertirán en riegos en los términos de Sax, Petrel, Elda y Novelda, quedando por consiguiente un remanente de 10 litros por segundo para destinarlos al uso de la ciudad de Alicante. Se indica que el proyecto piensa proseguir en más exploraciones a gran escala para aumentar el caudal de riegos y destinarlos a Monforte y Agost, y acrecer hasta en más del doble el destinado a esta capital de Alicante.

\section{La búsqueda del agua desde principios de siglo hasta los años cincuenta}

A comienzo de este siglo las numerosas tentativas planteadas con antelación para captar nuevos caudales resultaban efímeras ante el crecimiento continuo de los municipios del Campo de Alicante, que demandaban más recursos hidráulicos, tanto para abastecer a los núcleos urbanos o de población rural como para uso agrícola, que tendía a incrementar sus exigencias de agua debido a la nueva orientación del sector.

Los riegos suministrados por el pantano de Tibi seguían en esas fechas, y siguen hoy, con sus irregularidades y escaseces. Por otra parte, las aguas de avenidas, las de fuentes y las de norias, pertenecientes al Común o a particulares, no eran suficientes, agotándose a principio de siglo algunas de ellas, desapareciendo de la memoria de los lugareños. Esto motivó la necesidad de buscar ayuda en otros recursos que contribuyeran a paliar las deficiencias del sector y aseguraran la pervivencia de la huerta y del regadío en general, así como el abastecimiento de la población y la industria. Por ello surgen en los primeros años del siglo XX sociedades particulares que afrontaron momentáneamente la demanda de caudales, mediante las siguientes obras de infraestructura:

\section{1) El Canal de la Huerta de Alicante}

Se constituye en 1907 y empieza a suministrar agua a la Huerta en 1910. El agua se obtiene de 14 pozos artesianos situados en el paraje denominado el Zaricejo, término municipal de Villena. Se extrae mediante bombas con una potencia de 300 HP. y es conducida a través de un largo canal cubierto con una longitud de $68 \mathrm{Kms}$... Después de haber atendido algunas de las necesidades hídricas de los términos que atraviesa (Elda, Petrel, Novelda, Monforte del Cid) llega al Campo de Alicante y lo abastece. En el sector de la huerta se distribuye aprovechando la red general de acequias de la misma, con un caudal adquirido en propiedad por esta sociedad de 500 1/seg. ${ }^{22}$. Se utiliza el [28] sistema de vertedero, según el cual el agua es conducida por

\footnotetext{
${ }^{21}$ VIÑES MARTíNEZ, S. (1887), Memoria del proyecto de conducción de las aguas del Canal del Cid, Alicante. (Manuscrito sin paginar).

${ }^{22}$ GINER GONZÁLEZ, M. (1980): Opus cit. Pág. 168.
} 
medio de compuertas o paletas que reducen la velocidad del agua, con el inconveniente de la pérdida de fluido, aprovechado por otros agricultores si les llega a las lindes.

El agua de Villena es intransferible, pero de hecho se la prestan entre sí los campesinos, ya que el boleto es al portador. Se compra por $\mathrm{m}^{3}$, siendo el mínimo necesario 25 . Existe una queja generaliza entre los agricultores por las pérdidas de caudal, ya que la estimación total del usuario es de que sólo llega un caudal de 60-70 litros por segundo, lo que consecuentemente encarece el riego, ya que el precio de una hora de agua a principios de 1980 estaba sobre las 3.000 ptas., con un cupo de $400 \mathrm{~m}^{3}$, manteniéndose hoy estas tarifas, en precios fijados por la compañía en parecidas cantidades a los de Tibi.

\section{2) La mercantil «Riegos de Levante»}

Se trata de una compañía que surgió poco después de la anterior y que elevaba el sobrante en desembocadura de las aguas del río Segura $\left(5,1 \mathrm{~m}^{3} / \mathrm{seg}\right.$.) y de los azarbes de desagüe $(2,6$ $\mathrm{m}^{3} /$ seg.). Fundada esta sociedad en 1923, parte de estos volúmenes llegaron a Alicante en 1925, a través del llamado «tercer canal de Elche», de una longitud de $51 \mathrm{Kms}$ y que parte de la quinta elevación de Crevillente a $78 \mathrm{~m}$ sobre el nivel del mar.

El agua en la actualidad se vende directamente, aunque antaño se subastaba. La unidad de medida es la «cuarta» (hora y media de duración), equivalente a la «talla» huertana, con un caudal de $150 \mathrm{l} / \mathrm{seg}$., aproximadamente, que suponen $540 \mathrm{~m}^{3}$ en una hora. A la huerta llega muy mermada, siendo de 100 a 125 1/seg. lo que llega al terreno. Su precio normal está alrededor de 1.300 pts., llegando a cotizarse a 2.500 y 3.000 pts. la hora. El mínimo de tiempo que se puede comprar es, teóricamente, 20 minutos, pero en la realidad cada agricultor riega lo que necesita, siempre en el supuesto de que haya agua. Para su distribución también se utilizan las acequias propias de la huerta y el sistema citado de compuertas.

\section{3) La perforación de pozos}

A pesar del incremento de caudales que suponía la actividad de las compañías mencionadas, la demanda del sector agrícola provoca una continua inquietud traducida en nuevas fuentes de recursos. A los sistemas vistos de riego, hay que añadir uno nuevo, del que hemos expuesto sus precedentes y que desde mediados de los años 50 ya tiene gran auge en el Campo de Alicante, siendo en buena parte el que motive la proliferación de los embalses.

Es sin duda la perforación de pozos, que en otras zonas de la provincia (Villena, Marquesat, Albatera,...) tenían ya en estas fechas un gran desarrollo, la que da origen a una serie de transformaciones agrícolas que van a dejar su impronta en el paisaje. [29]

Estas perforaciones, que a principios de siglo utilizaban el gas-oil como fuente de energía básica, hoy se surten de la energía eléctrica, llenando los piedemontes con sus casetas y transformadores. Durante la primera mitad del siglo, los pozos y galerías se ubicaron en sectores deprimidos topográficamente, ya que estaban vinculados a bolsadas y mantos acuíferos cuaternarios propiciados por las deformaciones villafranquienses, coincidiendo con los emplazamientos elegidos por los núcleos de población, por lo que se encontraban en sectores periféricos de los mismos, donde se extendían las áreas de huerta tradicional. Esto ocurría en los regadíos de Alicante, Agost, San Vicente, y zona colindante con Monforte, donde además estos pozos aparecían indicados en muchas ocasiones con la presencia de balsas rústicas de mampostería y de pequeño tamaño que hacían, en sentido comparativo, el actual papel de los grandes embalses. Estas balsas de obra introdujeron un elemento peculiar por los años 50 y 60 en el paisaje agrario en el Campo de Alicante, y en general ocupaban las zonas de derrames de las ramblas, es decir, los llanos cuaternarios. En cambio, en los piedemontes y glacis más 
elevados y abruptos estos estanques no aparecían jalonando el parcelario. Hoy estas obras están en la mayoría de los casos convertidas en piscinas que se vacían de vez en cuando para regar los secanos cercanos a la finca-chalet o a la pequeña huerta cultivada a tiempo parcial. Algunas de ellas se encuentran inutilizadas, bien por abandono del terrazgo o por un hecho muy común que se viene dando en los últimos tiempos como es el agotamiento de los mantos acuíferos de estos sectores, por lo que, debido a ello, se han trasladado los cultivos de regadío hacia otras zonas con recursos hídricos.

Las áreas dedicadas a los cultivos de regadío en 1951, según indica López Gómez ${ }^{23}$ en su estudio de la Huerta de Alicante, quedaban relegados a sectores comprendidos entre las isohipsas de 100 y $120 \mathrm{~m}$. Igualmente se constata con el estudio de la fotografía aérea de esa época que las parcelas aisladas de regadío, localizadas en otros sectores del Campo de Alicante, no remontaban esas cotas. Este hecho contrasta enormemente con lo que sucede en la actualidad, en que la existencia de caudales superiores, algunas veces relacionados con los contactos de estratigrafías distintas en los piedemontes, y con los adelantos en técnicas hidráulicas permite la existencia de tierras regadas a alturas superiores a las referidas, incluso en torno a los 450-500 $\mathrm{m}$.

\section{LOS APORTES HÍDRICOS RECIENTES}

\section{Los sondeos}

Hay que tener en cuenta que las aguas procedentes de los nuevos sondeos que abastecen los regadíos del Campo de Alicante no pertenecen todos a esa comarca, sino que además de los tradicionales del Canal de la Huerta existen perforaciones fuera del sector, bien de compañías privadas o de Sociedades [30] Agrarias de Transformación, que a través de canalizaciones, a veces importantes, hacen llegar a esta zona caudales que luego son regulados en los nuevos embalses.

La existencia de estos pozos, tanto en el sector como en zonas próximas, está vinculada a la estratigrafía del Prebético meridional alicantino, con materiales jurásicos de areniscas (muy permeables), margocalizas (permeables) y margas en las sierras de Fontcalent, Mediana y Cabezón de Oro, y cretácicos de dolomías y calizas (muy permeables) en las sierras del Cid, Maigmó, Ventós, Águilas, Sabinar y Tajos ${ }^{24}$.

Esta estructura lítica, así como las directrices tectónicas que la afectan, propician la existencia de sistemas acuíferos. Por ello los principales sondeos en el sector en explotación se localizan en los piedemontes del Cabezón de Oro, Sierra Ventós, Tajos, Águilas y Mediana, y los más abundantes de la Sierra del Cid, y ya fuera del sector, los de Maigmó y Carrasqueta, Sax y Villena poseen los mayores aforos.

A la existencia de estos sistemas acuíferos se ve ligada directamente la presencia cada vez mayoritaria de los embalses de fibra impermeable, que deben su proliferación a la necesidad de almacenar un caudal continuo que surge de estos sondeos y que en épocas del año es infrautilizado, empleándose en otras más que al aforado por dichos pozos, nutriéndose las explotaciones agrarias, en esos momentos de mayor exigencia hídrica de las reservas almacenadas, de ahí la doble misión de almacenaje y regulación de caudales.

La importancia de estas nuevas captaciones ha ido en crecimiento en las últimas décadas

\footnotetext{
${ }^{23}$ LÓPEZ GÓMEZ, A. (1951), Opus Cit. Pág. 168.

${ }^{24}$ RODRÍGUeZ ESTRELlA, T. (1977), Sintesis geológica del Prebético de la provincia de Alicante. I) Estratigrafia; Bol. G.M. TLXXXVIII-III.
} 
debido, en primer lugar, a la gran demanda de agua por parte del sector agrícola, inmerso en la nueva tendencia de cultivos de invierno, y a los cada vez más limitados recursos hidráulicos en general, sobre todo superficiales. Debido a ello estas reservas hídricas son hoy objeto de múltiples estudios y planificaciones llevadas a cabo principalmente por el I.G.M.E. desde 1970 a través de un programa nacional de investigación de aguas subterráneas (P.I.A.S. $)^{25}$. En este sentido, el estudio realizado sobre la hidrogeología de la cuenca baja del Segura clasifica unos sistemas de acuíferos y plantea la situación de ellos, de los que entresacamos los que conciernen al Campo de Alicante. (Cuadro I.)

En estos momentos los caudales alumbrados se ven amenazados por el alarmante ritmo de descenso de los niveles piezométricos de los últimos años, del orden de 18 ó $20 \mathrm{~m}$ por año, cuestión preocupante, ya que parece que la continuada sequía que se padece y el exceso de sobreexplotación [31]

\begin{tabular}{|c|c|c|c|c|c|c|c|}
\hline \multicolumn{8}{|c|}{ CUADRO I } \\
\hline \multirow{3}{*}{ Sistema } & \multirow{3}{*}{$\begin{array}{l}\text { Volumen } \\
\text { import. } \\
\text { ded } \\
\text { exterior }\end{array}$} & \multicolumn{6}{|c|}{ Aguas subterráneas } \\
\hline & & \multirow{2}{*}{$\begin{array}{l}\text { Recarga } \\
\text { natural }\end{array}$} & \multicolumn{2}{|c|}{ Reserva } & \multicolumn{3}{|c|}{ Explotación } \\
\hline & & & Utiles & Totales & $\begin{array}{l}\text { Reservas } \\
\text { renorab. }\end{array}$ & $\begin{array}{l}\text { Reservas } \\
\text { sobre } \\
\text { explota. }\end{array}$ & Total \\
\hline $\begin{array}{l}\text { Terciario } \\
\text { Argueña-Maigmó } \\
\text { Sobreexplotado }\end{array}$ & $\mathbf{0}$ & 1 & $?$ & ? & 1 & 2 & 3 \\
\hline $\begin{array}{l}\text { Cretácico } \\
\text { Argueña-Maigmó } \\
\text { Sobreexplotado }\end{array}$ & 0 & 0 & $?$ & ? & 0 & 6,5 & 6.5 \\
\hline $\begin{array}{l}\text { Barrancones- } \\
\text { Carrasqueta } \\
\text { Sobreexplotado o } \\
\text { en equilibrio }\end{array}$ & 0 & 8 & $100-200$ & $?$ & 6 & 0 & 6 \\
\hline $\begin{array}{l}\text { Cid } \\
\text { Subexplotado o } \\
\text { en equilibrio }\end{array}$ & $\mathbf{0}$ & 1 & 200 & 200 & 1 & 20 & 21 \\
\hline $\begin{array}{l}\text { Cabezón del Oro } \\
\text { Sobreexplotado }\end{array}$ & 0 & 1 & 0 & 100 & 1 & 9 & 10 \\
\hline $\begin{array}{l}\text { Yecla-Villena- } \\
\text { Benejama } \\
\text { Sobreexplotado }\end{array}$ & 0 & 28 & $350-700$ & $?$ & 28 & 9 & 37 \\
\hline
\end{tabular}

I.G.M.E. (Plan nacional de investigación de aguas subterráneas).

Investigación hidrogeológica del Bajo Segura.

Colección-Informe. 1977. Pág. 62.

Cifras globales redondeadas y simplificadas en $\mathrm{hm}^{3} / \mathrm{año} \mathrm{y} \mathrm{hm}^{3}$.

no permiten la recarga freática y hace temer por el futuro de las inversiones y explotaciones. Los caudales de los sondeos en la zona son modestos, oscilando entre los 20 y los 60 l/seg., mientras que los sondeos que proceden de la zona de Sax y Castalla tienen caudales entre los 120 y 150 1/seg. Así pues las captaciones más sustanciosas se sitúan a largas distancias ( 27 y hasta $40 \mathrm{Km}$ ) de las parcelas y embalses a los que nutren, cuestión que incrementa notablemente el costo de dichas perforaciones, sin olvidar que ellas ya lo son en sí mismas, hecho este que ha condicionado que la sustracción y aprovechamiento de dichos caudales corra a cargo bien de empresas particulares con solvencia económica, o de grupos de transformación agrícola, limitando enormemente el acceso a los recursos del pequeño agricultor. Por otra parte, los sondeos del sector del Campo de Alicante presentan a menudo problemas de salinización, así

\footnotetext{
${ }^{25}$ I.G.M.E. (1977), Plan Nacional de Investigación de aguas subterráneas. Investigación hidrogeológica del Bajo Segura. Col. Informe, prólogo.
} 
como aforos reducidos que restringen a la vez que encarecen las posibles perforaciones. [32]

La problemática del agotamiento de estas reservas y las continuas prospecciones que se realizan, bien por particulares o por empresas, han planteado la posibilidad, por parte del Gobierno, de un plan de nacionalización de las aguas subterráneas.

\section{Las aguas depuradas}

Otro sistema de aprovechamiento hídrico que aún no ha alcanzado su apogeo en esta zona del Campo de Alicante, pero que intenta paliar en el futuro los problemas de escasez de agua, es la reutilización de las aguas residuales, alternativa que se viene planteando desde fines de los 70 y principios de los 80 , no siendo aún realidad en su totalidad.

De este modo el ciclo del agua se completa, primero abastece a la ciudad y luego se reaprovecha en la agricultura y la industria, pero la cantidad de productos químicos (sales y detergentes) hacen que la depuración no sea todo lo deseable que necesitaría para su utilización potable y agrícola, de ahí que sólo se use para regar ciertos cultivos, como las especies solanáceas, las cuales admiten más cloruros. Cuando todas las aguas residuales de la ciudad y urbanizaciones de la costa se depuren, el Campo de Alicante constituirá un modelo de aprovechamiento integral del agua. Objetivo que a corto plazo deben plantearse otros municipios próximos y con idénticas dificultades para la obtención del líquido elemento, tanto para fines agrícolas como industriales.

Los agricultores y empresas industriales de la comarca ven en este aprovechamiento una posible ayuda contra la lenta sangría que padecen los recursos superficiales y subterráneos. Se estima que el caudal reutilizable sería de $600 \mathrm{l} / \mathrm{seg}$., pero hasta ahora pocas son las explotaciones agrarias que se benefician. El único sector que percibe un caudal fijo en estos momentos es el área de tierras dedicadas al cultivo de hortalizas, ubicadas en la zona del Bacarot, piedemonte de Fontcalent, con un caudal de 80 1/seg. Se prevé para el año 85 la llegada desde la depuradora de Alicante de 123 1/seg., a las tierras de Monforte y Agost, a repartir al 50\% entre las dos sociedades agrarias de transformación existentes en estos dos municipios. También se ha ideado que estas aguas lleguen a través de una conducción de $30 \mathrm{Km}$ hasta algunos sectores del Vinalopó Medio que sufren los problemas de escasez y descenso de niveles acuíferos. Asimismo la depuradora de San Vicente recicla aguas que son aprovechadas por sectores de regadío del municipio, no obstante los caudales son modestos y los períodos en los que estas estaciones permanecen averiadas disminuye enormemente sus posibilidades. [33]

\section{El trasvase Tajo-Segura}

Este último sistema tuvo sus inicios en el anteproyecto aprobado en 1968 «Anteproyecto general de aprovechamiento conjunto de los recursos hidráulicos del Centro y Sureste de España, complejo Tajo-Segura». Aprobado en 1968, ha conocido tras largas demoras su puesta en funcionamiento a principio de los años ochenta.

De la dotación de $600 \mathrm{hm}^{3}$ que en la primera fase de funcionamiento del trasvase llegarían a la cuenca del Segura, $125 \mathrm{hm}^{3} /$ año correspondían a Riegos de Levante, Vega Baja del Segura y Saladares de Alicante, según la distribución hecha por comarcas y aprobada en Consejo de Ministros (equivaliendo a $5.300 \mathrm{~m}^{3} /$ ha y año).

En el Campo de Alicante no ha circulado todavía hoy agua de esta procedencia, que teóricamente debía llegar a través de Riegos de Levante hasta Campello. Sin embargo, Aguas Municipalizadas de Alicante sí que recibe agua para el abastecimiento de la ciudad a través de la Mancomunidad de Canales del Taibilla; debido a ello, e indirectamente, algunos regadíos sí que se benefician por medio del reciclaje que se efectúa con las aguas residuales depuradas, y 
que revierten a esta zona provenientes del Trasvase.

\section{EMBALSES DE PLÁSTICO}

Los primeros intentos de construir embalses impermeabilizados con fibra de polietileno se llevaron a cabo en el Campo de Alicante hace 25 años. Desde entonces la construcción de ellos no sólo se ha ido incrementando, sino que se han perfeccionado continuamente las técnicas. La euforia surgida en los primeros momentos por la búsqueda y captación de aguas subterráneas y su comercialización con fines agrícolas, ofreció por aquellos años unos buenos resultados, que fueron sin lugar a dudas el aliciente mayor que favoreció su desarrollo.

Varias son las razones por las cuales se podría justificar la necesidad de realizar este tipo de obras hidráulicas, y que a continuación se detallan:

$1^{\circ}$ ) Los embalses de plástico tuvieron su lugar dentro de las grandes explotaciones como medida preventiva del riego, ya que sufrían escasez de agua en gran parte del año, principalmente en verano, por lo que para asegurar los cultivos en esta estación tenían que almacenarla durante el invierno y la primavera.

$2^{\circ}$ ) Contribuye al auge de estas obras, en buena manera, el encarecimiento de la mano de obra, es decir, el gasto en las retribuciones de los jornaleros que realizan los riegos, cuyo aumento provoca situaciones económicas apretadas al propietario, ya que éste trata de efectuar el riego de noche en horas [34] en que el agua es más barata, aunque el riego nocturno viene encarecido por el jornal del acequiero, más elevado. Con los embalses, el agua se va acumulando durante la noche a menos costo y se utiliza cuando conviene, al día siguiente o en sucesivos.

$\left.3^{\circ}\right)$ El almacenamiento de agua nocturno se encuentra además vinculado a la mayor rentabilidad de una estación de bombeo cuanto más es el tiempo continuo de funcionamiento.

$4^{\circ}$ ) Durante la noche la energía es mucho más barata, por lo que las horas nocturnas de funcionamiento de las elevaciones aportan mayores beneficios en relación al consumo efectuado durante las horas del día. Extraen así los centros de bombeo agua que se acumula en estos embalses durante la jornada y que de no ser utilizada en ese momento queda almacenada para cuando sea necesaria.

$5^{\circ}$ ) Las recientes técnicas de «riegos localizados» (goteo, exudación y aspersión) necesitan en cabecera un estanque, aunque sea de tamaño reducido, para asegurar el funcionamiento de las instalaciones.

$\left.6^{\circ}\right)$ Por último, hay que indicar que los embalses han posibilitado la utilización de aguas de salinidades elevadas no aptas para ciertos cultivos, pero que mezcladas en ellos con otras de procedencia distinta y bajo contenido en cloruros y sulfuros se convierten en aprovechables. Esto posibilita que se incrementen los caudales disponibles por los agricultores.

Estas razones justifican además la pervivencia, economía y rentabilidad de una explotación. Por ello no es de extrañar que estas obras de elevados costos estén más propagadas donde el agua es más cara y donde las inversiones son más rentables, al combinarse con las condiciones físicas del medio y la proximidad a unos mercados de consumo del producto agrario. La inversión en la construcción de estos embalses se amortiza en cuanto se llenan dos o tres veces anualmente y en un período de tres a cinco años, quedando plenamente sufragados los gastos, por elevados que sean.

Los primeros embalses que se construyeron ${ }^{26}$ estaban ligados a explotaciones [35]

26 Periódico Información (9-10-1966), Feria de Orihuela, referencia a los primeros embalses de plástico construidos en España. El día de los embalses en la Feria de Orihuela la empresa I.M.S.A., propiedad de D. Carlos Mach, con sede en la calle Farada de Tarrasa, y con el delegado general para España D. José Gómez Abadía, calle Teodomiro, 10, de Orihuela, hace referencia a los construidos, que son los de las fincas:

-Los Garroferos, en la Algorfa, de 73.000 metros cúbicos. 


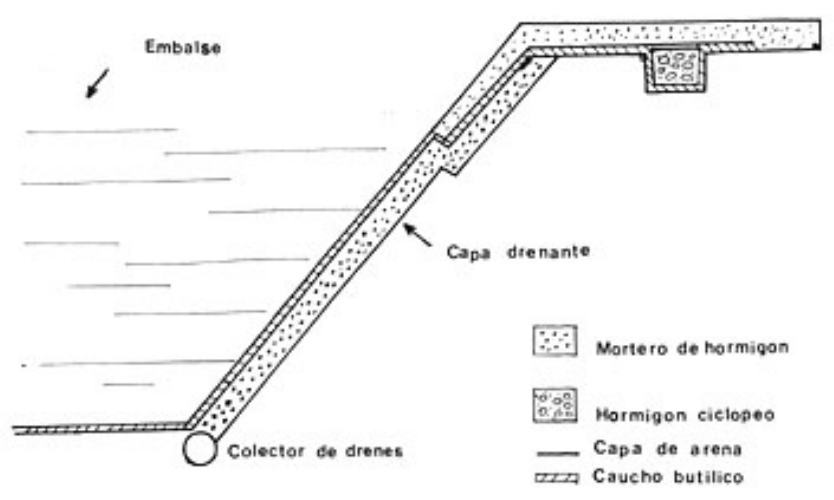

GRÁFICO 1. Esquema de la estructura del embalse de butilo. [36]

agrarias grandes y medianas. Al principio se hicieron de polietileno y más tarde de butilo, y sus capacidades iniciales estaban entre unos 5.000 y $60.000 \mathrm{~m}^{3}$, pero con el paso de los años la necesidad de un mayor almacenamiento en los meses de menor demanda para posteriormente abastecer con más disponibilidades en la época estival, obligó a la realización de embalses con capacidades superiores, alcanzando volúmenes de agua de $600.000 \mathrm{~m}^{3}$, como los de las obras de la S.A.T. de Monforte o el de Busot, con una capacidad de $1.400 .000 \mathrm{~m}^{3}$, perteneciente a BONNY S.A.

\section{Construcción de los embalses}

Comienza ésta por la selección de un lugar o situación ideal, con elevación natural conveniente y de amplitud adecuada a las posibilidades y necesidades reales de la explotación. Una vez elegido el enclave, siempre en sitio cimero que permita el riego por simple gravedad, se procede a los siguientes pasos: en primer lugar, la preparación del terreno y la compactación de los taludes de relleno que influyen directamente en la tensión del material, y los drenajes, factores que inciden en el comportamiento del material empleado en el revestimiento y en la propia seguridad del embalse; en segundo término, sistema de protección, toma de agua y desagüe; y en tercero, instalación del revestimiento del embalse artificial con una fibra impermeabilizante.

El sistema de compactación usual en embalses, de tipo medio (hasta $250.000 \mathrm{~m}^{3}$ ) con

-La Piqueta, Matadero-Cartagena, de 28.000 metros cúbicos.

-El Alto, Benferri, prop. de Manuel Gómez Pardo, de 32.000 metros cúbicos.

-Los Parrales, Jumilla, prop. de Lasa y G. ${ }^{a}$ Carrión, de 16.000 metros cúbicos.

-El Vino, Almoradí, prop. de José Navarro Guillén, de 85.000 metros cúbicos.

-La Capitana, Orito, prop. de Antonio Torres Murcia, de 60.000 metros cúbicos.

-El Raso Grande, Guardamar, prop. de Herederos de Puerto Galiana, de una capacidad de 72.000 metros cúbicos. 
alturas de talud de $12 \mathrm{~m}$ se realiza ya en principio, cuando se colocan las distintas capas de materiales sueltos, ayudándose para ello de tractores, palas, cargadoras, drumpers, bulldoozers y traíllas. Al mismo tiempo puede humedecerse el terreno mediante riego para mejorar la compactación. Posteriormente se acometerá el refino de fondo y de taludes, siendo lo esencial conseguir una superficie lo más fina posible y en la cual las gravas sueltas no excedan del tamaño malla de 2,4 centímetros. Se le puede pasar un rodillo de $8 \mathrm{Tm}$. y 1,5 m de ancho durante 20 veces. Si la ubicación del embalse lo permite, es aconsejable la extensión de una capa fina de arena de 57 centímetros como acabado, ya que mejoraría notablemente el comportamiento del revestimiento.

Los taludes deben tener una pendiente uniforme para evitar los cambios de tensión en las láminas. Se ha de procurar a la vez que su forma geométrica en planta sea mediante lados rectos para obtener una buena distribución de esfuerzos al $20 \%$, resultando una forma troncopiramidal. Gráfico n. ${ }^{\circ} 1$.

Se tiene que contar con el peso de la lámina $\left(1,2 \mathrm{Kgs} / \mathrm{m}^{2}\right.$ en espesores de $\left.1 \mathrm{~mm}\right)$ y el escaso rozamiento para calcular la tensión en el anclaje superior en función del talud elegido. Conviene que dicha tensión no origine un alargamiento superior al 20\% (tensión de trabajo) que daría lugar a un envejecimiento [37] prematuro de la lámina en esa zona. Por ello se recomienda otro $u$ otros anclajes en el talud en los casos de gran longitud del mismo (mayor de $36 \mathrm{~m}$ ) o gran pendiente.

Los embalses deben tener los drenajes en dependencia a su ubicación, al tipo de terreno, a la climatología, a la existencia de agua subterránea, etc. El fin primordial de éstos es eliminar los problemas que se pueden presentar de erosión y cavitación por arrastre de finos, subpresión debida al nivel freático y filtraciones o avenidas de zonas colindantes. Los drenajes pueden ser de dos tipos: continuos o parciales, los primeros formados a base de hormigones porosos asfálticos, hormigones porosos de cemento o también suelos y rocas bien graduados, y los segundos pueden ser de varias clases, según la función a realizar, aunque el más común es el tipo «dren» francés ${ }^{27}$, que consiste en una combinación de rocas, gravas, arenas y tubería perforada. La ubicación más frecuente de los drenajes en este tipo de embalses es en el talud de desmonte y deben estar situados, tras estudio geológico previo, uno a pie de talud y otro en coronación, mientras que en el fondo lo normal es la instalación de un drenaje perimetral. Este aspecto es de vital importancia pues evitaría la ruptura de ellos, hecho que se dio en el gran embalse de Busot, en 1979.

El sistema de protección evita el efecto de succión producido por el viento, ya que las fibras impermeabilizantes poseen una gran resistencia al efecto de los agentes atmosféricos en cuanto a lo oxidante.

Finalizadas las operaciones descritas, se instala la lámina impermeabilizante que reviste el embalse de obra, aunque previamente se ha de realizar un tratamiento con herbicidas. Las piezas de fibra sintética, de butilo o polietileno generalmente, han de ser lo mayores que permita su movimiento en obras, procurando que las juntas a solapar sigan el sentido de la pendiente, evitando en lo posible empalmes perpendiculares a la misma, al objeto de eliminar esfuerzos innecesarios en las solapas. Una vez extendidas sobre el talud las láminas a empalmar en la jornada de trabajo se sujetan provisionalmente en el anclaje superior. El solape se realiza mediante el «curing-tape» y posteriormente se vulcanizan las zonas entre láminas a solapar con máquina al uso. El tiempo de vulcanización es de 1 minuto a $10 \mathrm{seg}$. para espesores de $1 \mathrm{~mm}$ y temperaturas de la lámina de 25 a $30^{\circ} \mathrm{C}$, y 3 minutos para espesores de $2 \mathrm{~mm}$ e idéntica temperatura. Los anclajes de estas láminas impermeabilizantes mínimas son para la zanja

${ }^{27}$ Correo de la construcción (1980), 30 de noviembre al 7 de diciembre. Revestimiento de embalses artificiales, pág. 15. 
perimetral de $50 \mathrm{~cm}$ de ancho por $20 \mathrm{~cm}$ de profundidad, con separación mínima de $50 \mathrm{~cm}$ al borde del embalse. [38] Esta zanja puede rellenarse con piedras y tierras en embalses de tipo medio (hasta $75.000 \mathrm{~m}^{3}$ ). En embalses superiores se recomienda su llenado con hormigón ciclópeo, terminando en una plancha de hormigón que cubra la zona superior de la lámina hasta el borde interior superior, cumpliendo dos funciones, mejora de la resistencia al envejecimiento de la zona siempre expuesta a la insolación y aumento de anchura de la vía de coronación.

Por último, el llenado y desagüe se realiza de varias formas, que quedan resumidas en dos variantes, por la parte superior y por el fondo. En el primer caso, en el llenado es necesario instalar una canalización a lo largo del talud y al pie un disipador de energía para evitar los problemas de erosión y por lo tanto de ruptura. El vaciado puede realizarse mediante sifón en los embalses pequeños y por torre de vaciado con bombas aspirantes en los mayores. En el segundo caso, para su llenado se pueden utilizar una o varias tuberías que atraviesan el talud mediante un túnel visitable, desembocando en un cuenco amortiguador. Para vaciar se utiliza un sistema sencillo, en embalses de hasta $200.000 \mathrm{~m}^{3}$, consistente en una tubería de $250 \mathrm{~mm}$ de diámetro interior terminada en la forma necesaria para adaptarse al pie del talud. El acero va envuelto en otra tubería de cemento de $400 \mathrm{~mm}$ de diámetro, protegido todo ello por un macizado de hormigón pobre. Este sistema de vaciado es más inseguro y ha provocado en algunos de los embalses del Campo de Alicante diversas roturas (el embalse de Agost con tubería de fibrocemento en lugar de metálica, rompió por tronchamiento de la misma). La base de la obra es el punto más delicado de un embalse, por lo que se está rechazando en las nuevas construcciones este sistema de vaciado. Además en los grandes embalses este peligro es mayor, aplicándose en casos un sistema doble, que permite un vaciado rápido de emergencia y un vaciado de servicio mediante dos tuberías independientes.

Con estas características técnicas que se han detallado se vienen construyendo los embalses artificiales de plástico en los últimos años, aunque modernamente el avance en su edificación corresponde al empleo de revestimientos impermeables a base de caucho butílico, que ha demostrado ser por ahora el mejor material en la resistencia frente a los agentes atmosféricos y al continuo contacto con el agua y la presión misma de ésta. Sin embargo, no existe por hoy un material ideal que cumpla todas las exigencias de funcionamiento deseadas de duración y economía.

En un principio, inicios de los años setenta, estos estanques eran construidos por las propias empresas agrícolas o sociedades agrarias con técnicas rudimentarias y con fibras impermeabilizantes comunes, plásticos o polietilenos, simplificándose mucho el proceso de construcción en todas sus etapas. La diferencia básica con los de caucho butílico es la instalación del revestimiento del embalse con la fibra impermeabilizante, que es de lámina de polietileno 


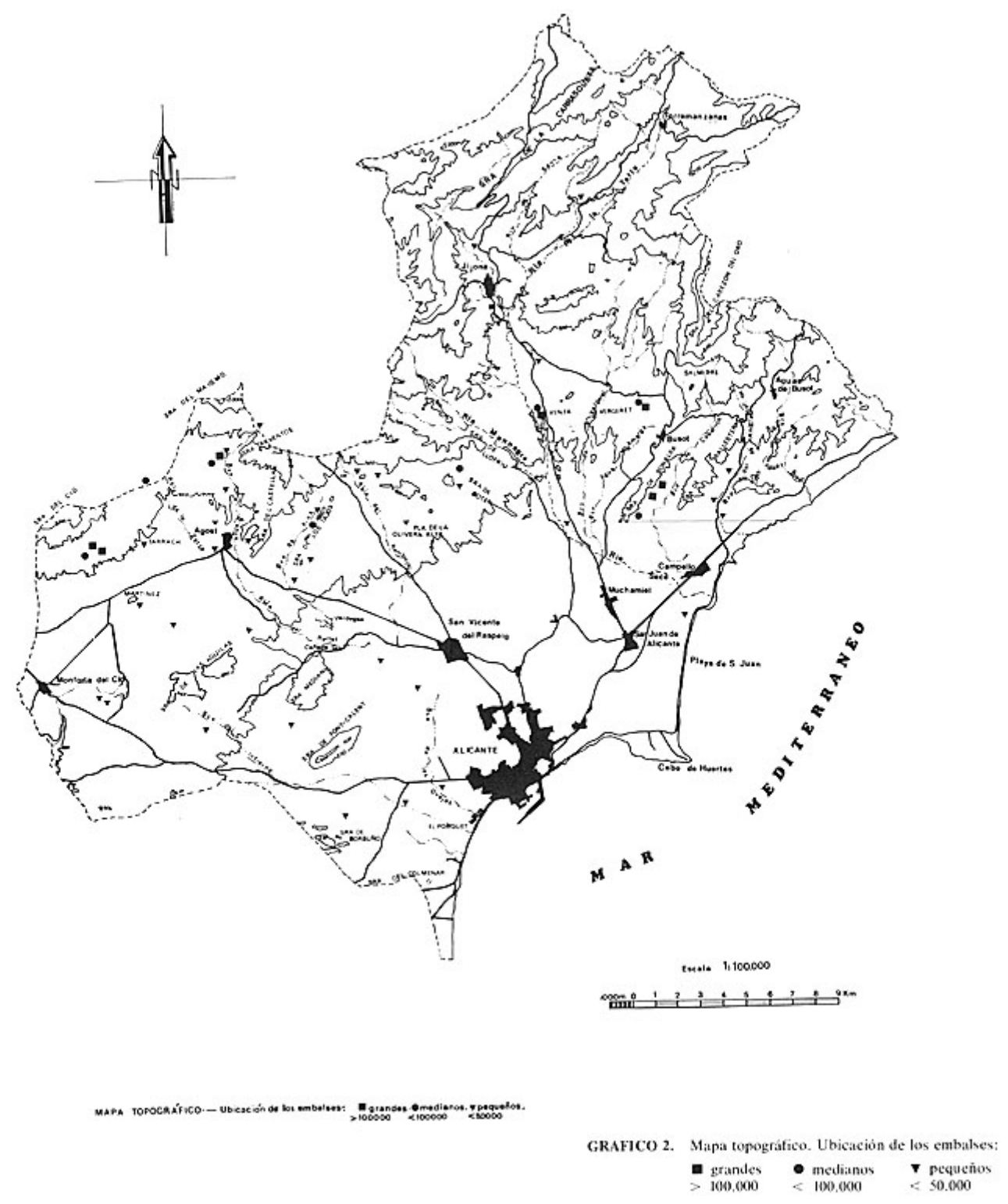

[39]

o plástico de 1.000 galgas, colocada entre dos capas de arena de $20 \mathrm{~cm}$ de espesor cada una, cubriéndose la capa superior de arena con otra de grava y cantos rodados para evitar que, una vez lleno el estanque, la arena superior sea arrastrada por el agua al fondo, dejando al descubierto el polietileno y pudiendo ser fácilmente atacado por los agentes atmosféricos. Hoy se sigue utilizando esta técnica para los embalses de pequeñas dimensiones, entre 5 y $25.000 \mathrm{~m}^{3}$, ya que las tensiones a soportar, generalmente, no requieren mayores gastos en técnicas constructivas más sofisticadas.

Actualmente las construcciones que estudiamos corren a cargo de compañías especializadas, que actúan con pólizas de seguro internacionales y ofrecen hasta 10 años de 
garantía. Se emplea generalmente láminas de butilo, con valores del triple de los de película de polietileno, aunque su seguridad es mayor y son más apropiados para embalses grandes, necesitando de medidas mayores de garantía, como los situados en la zona, de entre 600.000 y $1.400 .000 \mathrm{~m}^{3}$. Los de polietileno, según Vera Rebollo ${ }^{28}$, a principios de la presente década tenían los siguientes precios:

Embalses de 1.000 a $5.000 \mathrm{~m}^{3}: 85 / 90 \mathrm{pts} . \mathrm{m}^{3}$.

Embalses de 5.000 a $10.000 \mathrm{~m}^{3}: 80 / 85 \mathrm{pts} . / \mathrm{m}^{3}$.

Embalses de 10.000 a $20.000 \mathrm{~m}^{3}: 70 / 75 \mathrm{pts} . / \mathrm{m}^{3}$.

Embalses de 20.000 a $50.000 \mathrm{~m}^{3}: 65 / 75 \mathrm{pts} . \mathrm{m}^{3}$.

Embalses de 50.000 a $100.000 \mathrm{~m}^{3}: 55 / 65 \mathrm{pts} . \mathrm{m}^{3}$.

Un embalse de polietileno de $100.000 \mathrm{~m}^{3}$ supera hoy los diez millones de pesetas.

Los precios para embalses de butilo se multiplican por 6 y hasta por 10 veces sobre los anteriores. Así en $1981 \mathrm{el} \mathrm{m}^{3}$ de fibra de vicón costaba 425 ptas. y de caucho butílico 600 pts. ${ }^{29}$. La duración normal de estas construcciones es de 6 ó 7 años, y puede llegar a los 12 si tiene buenas condiciones de mantenimiento y no se las deja vacías durante largo tiempo, siendo los de butilo más resistentes.

Como ya se expuso, el enclave de estos embalses viene decidido por el punto más alto de la explotación, para que se pueda practicar el riego por gravedad. Esta circunstancia es más apreciable en los grandes, que en algunos casos poseen una doble función, de almacenaje y mezcla de caudales, teniendo que situarse en lugares estratégicos para atender a necesidades comunitarias de las tierras abarcadas por él. Además, los enclaves elegidos se encuentran perfectamente comunicados, pese a la altura en que se localizan, [40] ya que una buena red de caminos y carreteras permiten el fácil acceso a todos los servicios necesarios en cada momento, así como el paso de los asociados a su explotación.

Importante en la ubicación de los embalses es el medio geológico en que se asientan, ya que estas obras ocupan niveles de glacis preferentemente superiores y piedemontes, constituyendo a su vez basamentos extraordinarios que facilitan la realización de los mismos, es decir, acortan enormemente los gastos de la construcción, así como el trabajo, pues los materiales básicos de infraestructura se encuentran en el lugar (gravas y arenas). Por otra parte, el trabajo de apisonamiento (prensado) y compactación de los diversos pisos del basamento se reduce enormemente en este sector del Campo de Alicante, igual que en otras zonas del SE peninsular, puesto que los limos encostrados que componen la mayor parte de estas morfologías semiáridas reducen en buena manera el proceso descrito.

En muchos casos, los embalses del sector reciben aguas de otras comarcas colindantes, de ahí que a veces su localización responda a las áreas inmediatas a esas zonas, a fin de evitar costos en el transporte del agua. A ello responde la ubicación de los embalses de las grandes explotaciones, SAT de Monforte del Cid, que importa el agua de la zona de Sax, SAT de Agost (Plá Aceituna), que recibe el agua de Biar, los de BONNY o ETASA, que recogen el agua de Castalla y de Onil. La ubicación de los grandes embalses utilizados por estas empresas agrarias está sobre el piedemonte de sierras prebéticas que circundan el Campo de Alicante por el norte y que marcan la separación de la cuenca vertiente de esta comarca con sus vecinas más próximas de donde se están obteniendo los caudales que hoy les alimentan.

\footnotetext{
${ }^{28}$ VERA REBOLLO, F. (1981): Tradición y cambio en el campo del Bajo Segura, Facultad de Filosofía y Letras, Alicante.

${ }^{29}$ Datos ofrecidos por la S.A.T. de Agost «Plá Aceituna» y el Instituto para la Reforma y Desarrollo Agrarios.
} 
Gran parte de los caudales que retienen estos embalses proceden de otras áreas, teniendo entonces que construir unos canales que en ocasiones llegan a tener varios Kms de recorrido (de 30 a $50 \mathrm{Kms}$.). Estas conducciones están adaptadas a una capacidad de entre 200 y 300 1/seg., siendo de cemento armado a fin de soportar fuertes presiones que vienen provocadas por los grandes desniveles topográficos de los lugares que atraviesan. Por el contrario, los que tienen su origen en los sondeos del lugar llegan al pantano artificial a través de tuberías de menor presión e incluso de canales abiertos desde los centros de bombeo. Estas diversas fuentes de aprovisionamiento permiten realizar en muchas explotaciones mezclas con aguas de distintas procedencias para mejorar la calidad de alguna de ellas, que de no ser así no serían aptas para el riego.

Las aguas que se obtenían normalmente dentro del Campo de Alicante dado el fuerte proceso de extracción, descenso de niveles y proximidades en ocasiones de materiales del Keuper, poseen altos contenidos en sulfatos y cloruros convirtiéndolas en nada aptas para el regadío. Por el contrario, las que se [41] obtienen en los estratos cretácicos del prebético presentan porcentajes de cloruros y sulfatos mucho más bajos, siendo por esta causa las más cotizadas, ya que sirven para mezclarlas con las anteriores y reducir así su salinidad ${ }^{30}$.

Desde los embalses salen canales con capacidad para caudales medios de alrededor de 150 y 200 1/seg., aunque en algún caso se llegue hasta 400. El principal recorre las explotaciones desde el talud del embalse hasta el lugar más alejado de ella, en sentido de la pendiente. Partiendo de este ramal y en los distintos tramos del recorrido salen canales secundarios con capacidades menores, en general 50 l/seg., y de éstos otros subramales con distintas secciones que hacen llegar el agua a todas las parcelas. En algún caso a la salida del agua de los embalses se encuentran estaciones distribuidoras funcionando a modo de partidores que dividen desde el primer momento el agua hacia diferentes canales principales que se ramifican dentro de la explotación.

Esta técnica de distribución es la que se realiza con mayor difusión en los casos analizados, ya que prevalece el riego tradicional a manta, pero se tiende a introducir el riego a goteo, ya que limita mucho más el consumo de agua, ahorrando mano de obra y aumentando la

${ }^{30}$ En este sentido baste comparar sendos análisis de agua pertenecientes a la SAT «Plá Aceituna» de Agost de sondeos realizados en los límites de dicho municipio.

Muestra 1.447. Analizada en 2-9-80:

Sodio (Na)....................................... $1,2 \mathrm{me} / \mathrm{l}$.

Calcio (Ca)...........................................3,5 me/l.

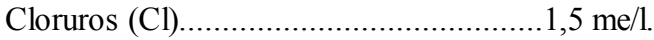

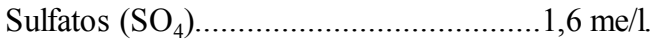

Salinidad efectiva.................................1,4 me/l. frutales).

Corresponde a 0,09 $\mathrm{g} / \mathrm{l}$. de cloruro sódico $(\mathrm{CINa})$. Agua útil para el riego en general (destinada a viña y

Muestra 30.365. Analizada en 7-3-83:

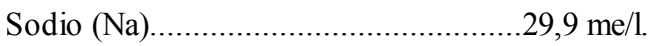

Calcio (Ca)............................................27,0 me/l.

Cloruros $(\mathrm{Cl}) \ldots \ldots \ldots \ldots \ldots \ldots \ldots \ldots \ldots \ldots \ldots \ldots . . . . . . . . . . . . . . . . . .35,9$ me/l.

Sulfatos $\left(\mathrm{SO}_{4}\right) \ldots \ldots \ldots \ldots \ldots \ldots \ldots \ldots \ldots \ldots \ldots . . . . . . . . . . . . . . . . . .37,7 \mathrm{me} / \mathrm{l}$.

Salinidad efectiva...............................49,9 me/l.

Corresponde a 2,08 g/l. de cloruros. Agua inútil para el riego de uva de mesa, para el que se la quería utilizar en principio.

Ambos análisis fueron realizados en los Laboratorios de suelos, abonos y fertilidad de AGRINCA (Alicante). 
cosecha y la calidad de ésta. No obstante, los costes elevados de la instalación y la necesidad de mano de obra cualificada para su manejo ha hecho que dicha técnica de riego más sofisticada no se prodigue todavía mucho en estos sectores. Para este sistema de riego, el agua necesitaría al salir del embalse pasar por una estación donde estaría el cabezal de filtrado y el sistema de impulsión, así como el programador de estaciones. De aquí pasaría a una red de tuberías especial, que conserva la presión hasta $6 \mathrm{Kgs} / \mathrm{cm}^{2}$, para finalmente pasar a los goteros y a las plantas. [42]

\section{IMPACTO PAISAJÍSTICO DE LOS EMBALSES}

Las nuevas formas de captación, almacenamiento y reparto del agua en el campo alicantino se han dejado sentir de manera muy ostensible. Los tradicionales secanos, con predominio de cultivos de almendros y algarrobos, han sido sustituidos por áreas de regadío que contrastan enormemente con las parcelas que han quedado de aquéllos. Pero tal vez las mutaciones que más sorprenden son las relacionadas con las obras hidráulicas que se han venido haciendo en los últimos años: los embalses de plástico. Destacan éstos en una doble vertiente: por su monumentalidad y por el gran número que de ellos se han construido. Se han contabilizado 54 construcciones, distribuidas en el Campo de Alicante, formando núcleos de 3 ó 4 embalses conectados y pertenecientes a una misma explotación, o diseminados. En el primer caso las concentraciones de estas obras hidráulicas se deben, en la mayoría de los casos, a una coordinación existente entre ellas que abastece a propiedades particulares muy extensas o a sociedades Agrarias de Transformación y se localizan en tres sectores bien definidos: los valles de Busot y Jijona, donde radican las sociedades particulares de BONNY S.A. y ETASA, con cinco embalses la primera y dos la segunda; el valle de Agost, donde hay dos estanques de la SAT «Plá Aceituna»; y el piedemonte E y SE de la Sierra del Cid, en el que se instalan tres embalses pertenecientes a la SAT de Monforte del Cid. Estas agrupaciones son de un gran impacto paisajístico, ya que además aglutinan las obras de mayores capacidades, que oscilan entre los $50.000 \mathrm{~m}^{3}$ y los $1.400 .000 \mathrm{~m}^{3}$, y que surten a grandes extensiones de regadío, entre 1.500 y 3.000 ha.

En el otro caso sus capacidades son más reducidas y por ello proliferan más y están en continua expansión, ya que su construcción la pueden acometer pequeños y medianos propietarios, siendo su impacto paisajístico menor que en el caso anterior, al faltar la monumentalidad y constituir obras aisladas. (Cuadro II).

La presencia de caudales aforados de estos nuevos sondeos, así como las diversas formas sociales de explotarlos, han posibilitado un fenómeno de transformación y cambio en el paisaje rural de esta comarca. De los antiguos secanos que dominaban estos mismos sectores, cultivados con cereales, almendros y algarrobos, en las áreas de piedemontes, y olivos en los valles y lechos de ramblas, y que quedan patentes en los análisis de fotointerpretación realizados sobre material del año 56, así como en parcelas que quedan hoy por transformar, se pasa a partir de los años setenta a cultivos de regadío que han introducido cambios radicales en el paisaje.

Se tienen datos fidedignos de que han sido transformadas 12.000 ha, y es estimable que a esta superficie se sumen otras 6.000, que no están registradas, pero que son detectables mediante análisis cartográfico, habiéndose dedicado principalmente a cultivos de gran rentabilidad, entre los que destacan la uva de mesa y el tomate de invierno, que mantienen porcentajes similares de [43] ocupación del suelo dentro de estas áreas regadas. En las zonas costeras, piedemontes litorales de Fontcalent, Sierra del Colmenar, Bacarot y Borbuño, priman los hortícolas, ocupando además los sectores de la Cuenca de Busot, Jijona y los antiguos dominios de la Huerta. En cambio las áreas interiores de los valles de San Vicente, Agost y Monforte, están ocupadas casi totalmente por cultivos de vid en parral y espaldera. (Cuadro III).

Estas mutaciones en los cultivos y la consiguiente transformación del secano tradicional 
a los nuevos regadíos, están contribuyendo a crear en la periferia alicantina un cinturón verde de huertas que rodean a la ciudad, y que ha sido un anhelo deseado durante largo tiempo, matizado ya al comienzo del estudio en las distintas alusiones históricas sobre la búsqueda y captación de aguas para el riego. Este entorno de regadío resulta más asombroso paisajísticamente si se contrasta con la idea secular de la semiaridez del campo de Alicante.

Si morfológicamente estos embalses de plástico han contribuido de forma notoria a la transformación del medio rural, también lo han hecho desde el punto de vista socioeconómico, ya que de una parte han aumentado la rentabilidad de una tierras, fomentando el crecimiento del nivel de vida de esos municipios, que aglutinan mayores cupos de mano de obra, sobre la que revierten grandes beneficios. Por último, hay que hacer mención al papel realizado en la aparición de nuevos sistemas de tenencia y propiedad del agua, en base a los distintos procesos que existen para su explotación, y que vienen resumidos en un efecto cada vez mayoritario de privatización de las reservas hídricas en base a los grandes costos necesarios para su obtención. [44]

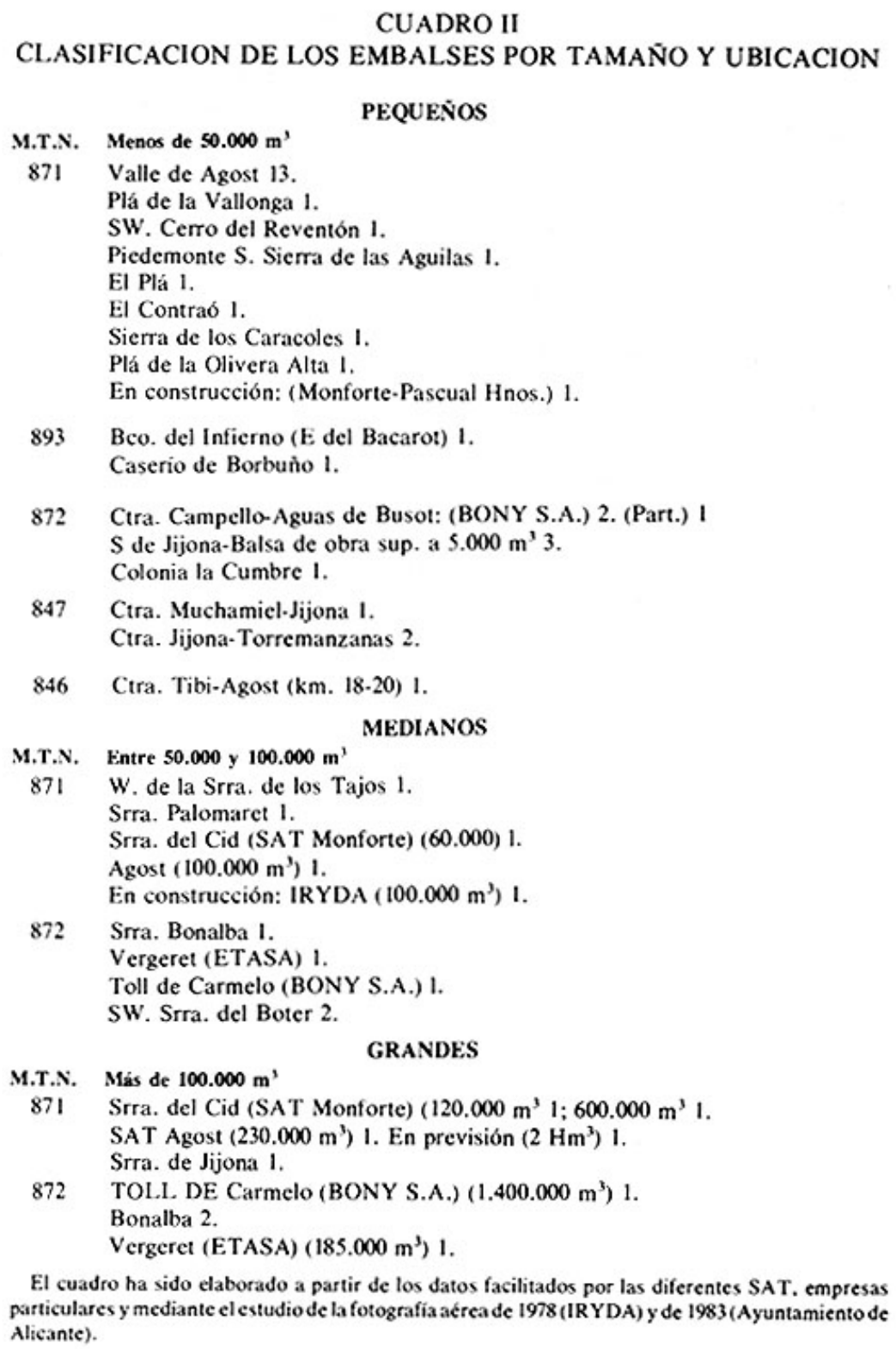

El cuadro ha sido elaborado a partir de los datos facilitados por las diferentes SAT. empresas particulares y mediante el estudio de la fotografia aérea de 1978(IR YDA) y de 1983 (Ayuntamientode Alicante). 
CUADRO III

ESTRUCTURA ECONOMICA DE DOS S.A.T,

\begin{tabular}{|c|c|c|}
\hline Datos referentes 1983 ' & $\begin{array}{l}\text { SAT Número 2336-735 } \\
\text { Monforte del Cid (1962) }\end{array}$ & $\begin{array}{c}\text { SAT de Agost } \\
\text { Pla Aceituna (1976) }\end{array}$ \\
\hline Capital social & 129.927 .123 pts. & 145.277 .500 pts. \\
\hline Resguardos nominativos & 125.400 & 25.450 \\
\hline Valor resguardo & $1.036 .10 \mathrm{pts}$ & 5.708 .35 pts. \\
\hline Valor en Tahúllas y m. ${ }^{2}$ & $\begin{array}{l}0.25 \mathrm{Th} . \\
269.50 \mathrm{~m}^{2}\end{array}$ & $\begin{array}{l}0,50 \mathrm{Th} . \\
600,50 \mathrm{~m} .^{2}\end{array}$ \\
\hline Socios & $1.300 / 2.000$ & $432 / 500$ \\
\hline Pozos & $\begin{array}{l}\text { 4. Sierra del Cid. } 300 \mathrm{~V} / \mathrm{s} \text {. } \\
\text { 2. Sierra Larga. } 300 \mathrm{~V} / \mathrm{s} \text {. } \\
\text { 3. Sax. } 350 \mathrm{~V} / \mathrm{s} \text {. } \\
\text { Varios sondeos cerrados. }\end{array}$ & $\begin{array}{l}\text { 1. Biar (Hoya de Castalla). } \\
\text { iso-125 } / \mathrm{s} \text {. } \\
\text { 2. Agost. Cerrados por salini- } \\
\text { dad del agua. } 10 \mathrm{~V} / \mathrm{s} \text {. }\end{array}$ \\
\hline Embalses & 1. $60.000 \mathrm{~m}^{3}$ & $\begin{array}{l}\text { 1. En proyecto (Estado) } \\
2 \mathrm{Hm} \text {. }\end{array}$ \\
\hline & $\begin{array}{l}\text { 1. } 120.000 \mathrm{~m}^{3}{ }^{3} \\
\text { i. } 600.000 \mathrm{~m} .\end{array}$ & $\begin{array}{l}\text { 1. } 230.000 \mathrm{~m} .{ }^{3} \\
\text { 1. En proyeción para aguas } \\
\text { residuales. IRYDA. } 100.000 \mathrm{~m} \text {.' }\end{array}$ \\
\hline Superficie regable & $\begin{array}{l}1.50 .000 \mathrm{~m} . \\
32.000 \mathrm{Th} / 40.000 \\
3.500 \mathrm{Ha}\end{array}$ & $\begin{array}{l}13,000 \mathrm{Th} . \\
1.561,3 \mathrm{Ha} .\end{array}$ \\
\hline Cupo de agua por socio & $\begin{array}{l}2 \mathrm{~h} \text {. de agua por Th. } y \text { ano. } \\
\text { Cubicaje: } 216 \mathrm{~m} .3 / \mathrm{h} \text {. }\end{array}$ & $\begin{array}{l}500 \mathrm{~m} .{ }^{3} \text { de agua por Th. } \\
\text { y año. } \\
\text { (Este ap̧o no ha llegado a los } \\
200 \mathrm{~m} \text {,). }\end{array}$ \\
\hline $\begin{array}{l}\text { Necesidad de riego cultivo } \\
\text { uva de mesa }\end{array}$ & $\begin{array}{l}30 \mathrm{~min} \text {. a } 45 \mathrm{~min} \text {. por Th. } \\
250 \text { plantas por Th. } \\
7 \text { millones de m. }\end{array}$ & $\begin{array}{l}1,5 \mathrm{~m}^{3} \text { por planta. } \\
2,5 \text { millones de } \mathrm{m}{ }^{3} \text { al año. }\end{array}$ \\
\hline $\begin{array}{l}\text { Precio del agua (mantenido en } \\
7 \text { años }\end{array}$ & $\begin{array}{l}\text { Precio base: } 2.500-3.000 \text { pts.-h. } \\
\text { Subastas (según épocas): } \\
6.000-7.000\end{array}$ & $\begin{array}{l}2.300 \mathrm{~m}^{3} / \mathrm{h} . \text { Fijo. } \\
14 \mathrm{pts} . / \mathrm{m}^{3}\end{array}$ \\
\hline Tarifa eléctrica & $\begin{array}{l}0,6 \text { y } 0,99 \mathrm{pts} / \mathrm{Kw} \text {. } \\
\text { (20 y } 30 \mathrm{mill} \text {. en fluido) }\end{array}$ & 7 y $10 \mathrm{pts} / \mathrm{m}{ }^{3}$ \\
\hline & (al año). & $\begin{array}{l}\text { 1.035.324 pts. en junio } \\
\text { Depende de la de- } \\
\text { manda y la época. El } \\
\text { trabajo nocturno su- } \\
\text { pone redueciones del } \\
10 \text { al } 30 \% \text {. }\end{array}$ \\
\hline Infraestructura & $\begin{array}{l}100 \mathrm{~km} \text {. de tuberias (IRYDA). } \\
70 \mathrm{~km} \text {. Caminos (IRYDA). }\end{array}$ & $\begin{array}{l}40 \mathrm{~km} \text {. de tuberias (IRYDA). } \\
\text { Caminos propios. }\end{array}$ \\
\hline Embalses & 3 con ayuda del IRYDA. & I con ayuda del IRYDA. \\
\hline $\begin{array}{l}\text { Periodo de almacenaje } \\
\text { de agua }\end{array}$ & Septiembre-enero & Septiembre-enero \\
\hline $\begin{array}{l}\text { Periodo de riegos: } \\
2 \text { anuales }\end{array}$ & $\begin{array}{l}\text { (1)Enero-marzo. } \\
\text { (2) Mayo-agosto. }\end{array}$ & $\begin{array}{l}\text { (1) Enero-marzo. } \\
\text { (2) Mayo-agosto. }\end{array}$ \\
\hline Créditos de funcionamiento & \multicolumn{2}{|c|}{$\begin{array}{l}20 \% \text { intereses de las Cajas a } 1 \text { y } 2 \text { años. } \\
17 \% \text { Banco de Crédito Agricola a } 7 \text { años. } \\
7 \text { y } 11 \% \text { IRYDA. } 10 \text { años y a través de las Cajas Rurales. }\end{array}$} \\
\hline
\end{tabular}




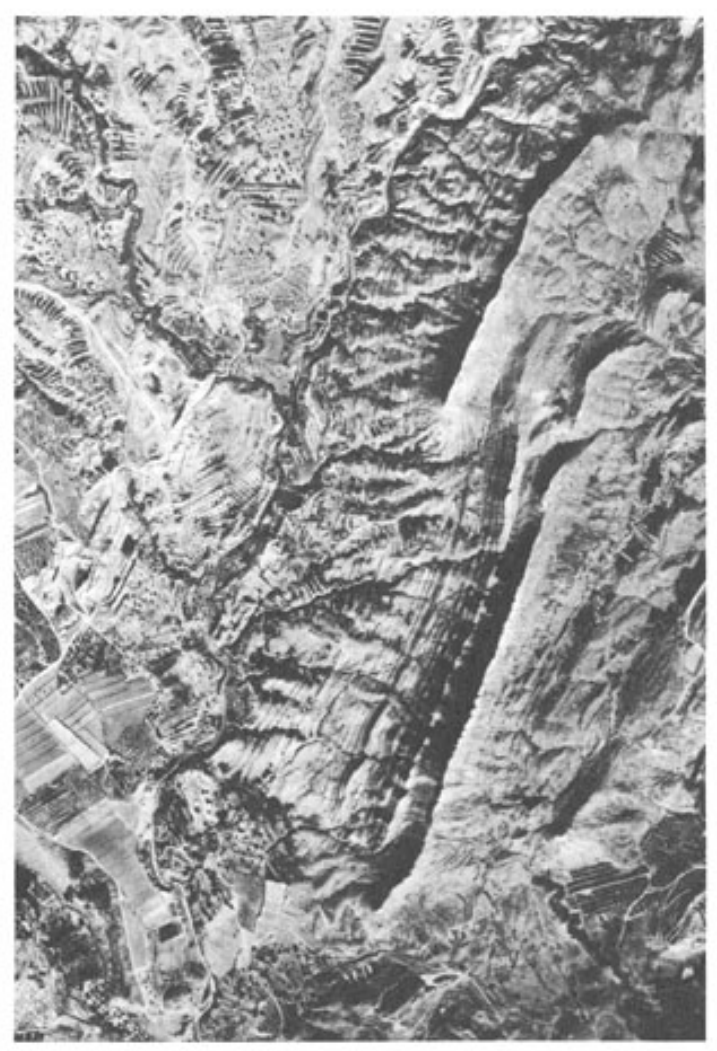

FOTO 1. Estado del piedemonte Occidental de la Sierra de los Tajos según la fotografía aérea del vuelo de 1978 realizada por el IRYDA. En ella se aprecian los cultivos tradicionales y el inicio del proceso de transformación. [47] 


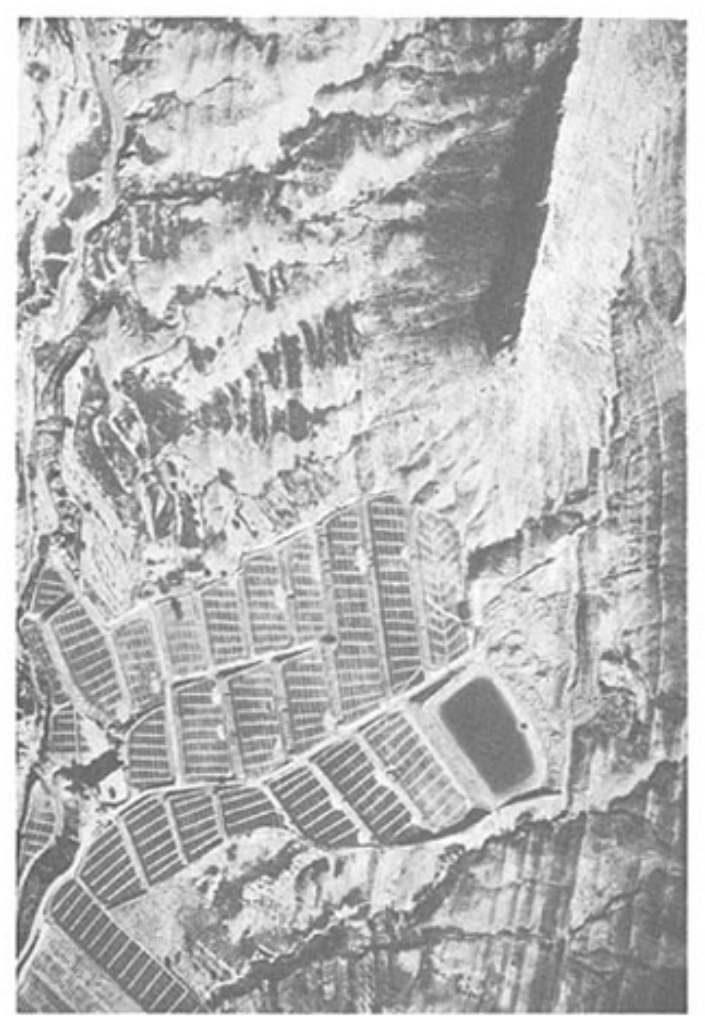

FOTO 2: Nuevo parcelario agrícola y embalse de butilo realizado en el piedemonte de la sierra de los Tajos que en la foto número 1 estaba todavía de erial. Octubre 1983. [48]

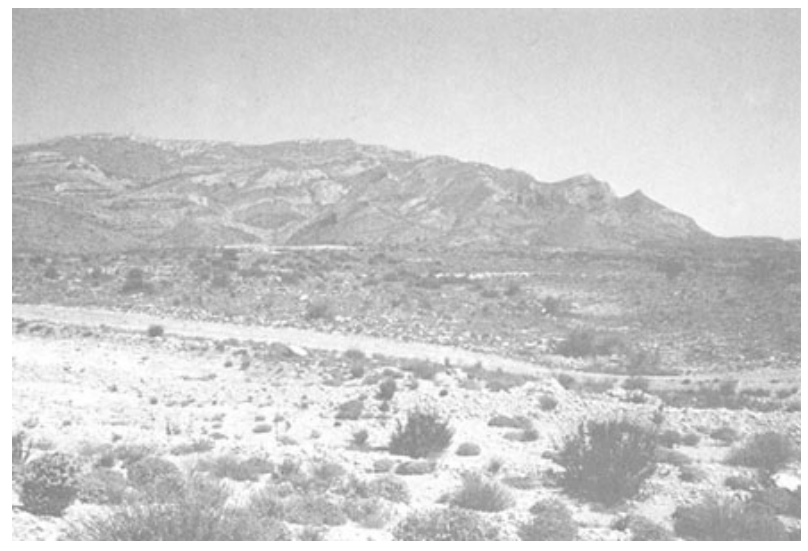

FOTO 3. Arranque del glacis N. E. al pie de la Sierra del Cid en el estado anterior a su utilización para la construcción de embalses. Se observa claramente una topografía poco accidentada recubierta por costra calcárea lo que convierte al lugar en un área idónea para tal fin. 


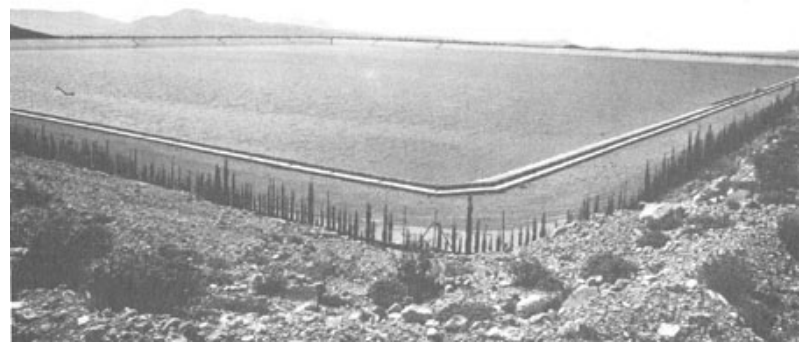

FOTO 4. Embalse de butilo de $600.000 \mathrm{~m}^{3}$ de capacidad perteneciente a la S.A.T. de Monforte. Su vaciado se realizó sobre parte del glacis de la fotografía precedente.

Desde él se inicia una red de canalizaciones que distribuyen las aguas entre los términos de Agost y Monforte. [49]

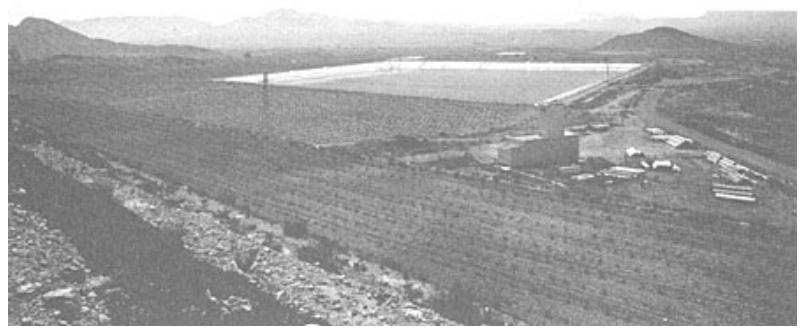

FOTO 5. Panorama de un embalse de butilo de $120.000 \mathrm{~m}^{3}$ de capacidad en medio de un área transformada para el cultivo de uva de mesa. En primer término se ve el centro de bombeo de un pozo, que se utiliza para alimentarlo. Dicho embalse pertenece igualmente a la S.A.T. de Monforte.

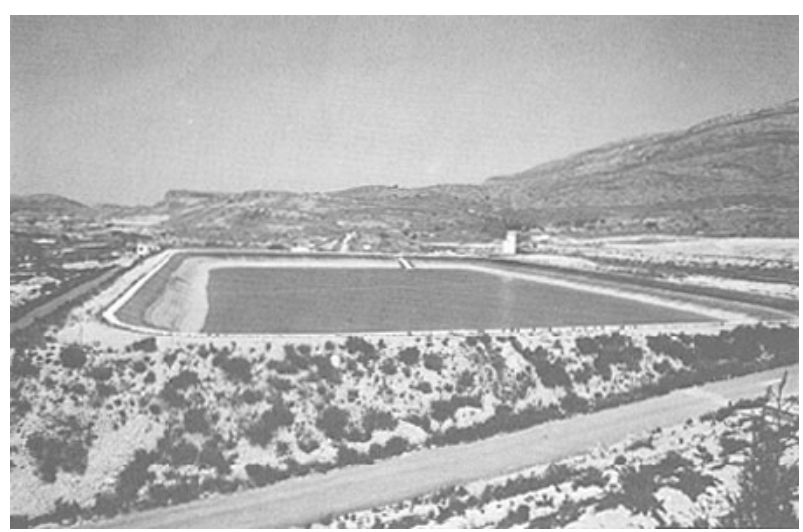


FOTO 6. Embalse de butilo de Agost con capacidad de $230.000 \mathrm{~m}^{3}$. Se aprecia claramente la técnica de su construcción, tanto del aprovechamiento de la topografía del glacis, como de los materiales del talud de la parte más baja y de la lámina de butilo que lo reviste. [50]

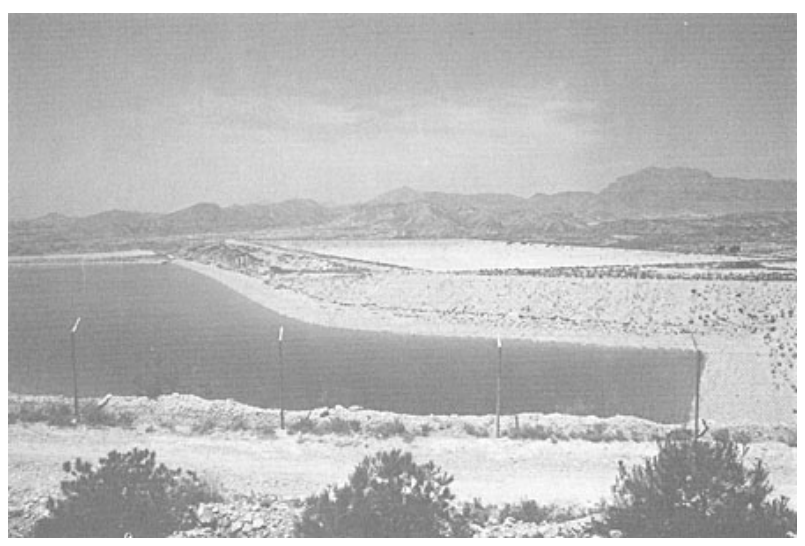

FOTO 7. Dos embalses de polietileno con capacidades de $1.400 .000 \mathrm{~m}^{3}$ el mayor y 60.000 el menor hechos aprovechando un Lambeaux de glacis de la Sierra del Cabeço D’Or. Esta utilización del resto de glacis es la que ha obligado a adoptar la forma irregular del embalse que se ve en primer lugar. 


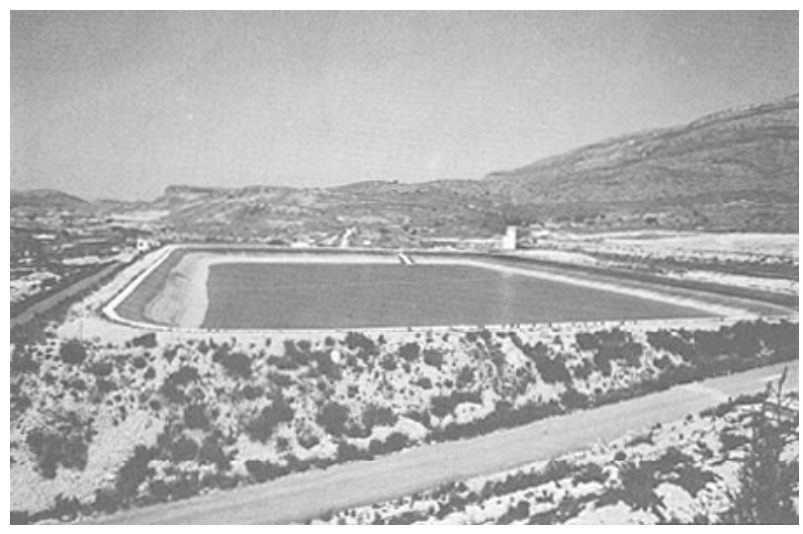

FOTO 8. Paisaje agrario de un área transformada con el agua procedente de los embalses de plástico en el piedemonte de la Sierra de Bonalba. Se ven claramente tres estadios muy diferenciados:

1) un área de erial correspondiente a unas parcelas en las que se cultivó tomate, 2) al frente en su parte izquierda una zona preparada, para el cultivo de tomate de invierno y 3) al fondo se ven invernaderos de plástico para cultivos hortícolas. 